Penultimate draft of chapter forthcoming in Parental Responsibility in the Context of Neuroscience and Genetics, eds. Kristien Hens, Dorothee Horstkötter, and Daniela Cutas, Dordrecht: Springer

\title{
Normative responsibilities: structure and sources
}

Gunnar Björnsson and Bengt Brülde

Attributions of what we shall call normative responsibilities play a central role in everyday moral thinking. It is commonly thought, for example, that parents are responsible for the wellbeing of their children, and that this has important normative consequences. Depending on context, it might mean that parents are morally required to bring their children to the doctor, feed them well, attend to their emotional needs, or to see to it that someone else does. Similarly, it is sometimes argued that countries that emit most greenhouse gases have most responsibility for preventing catastrophic climate change. This responsibility might imply that these countries are morally required to take necessary steps individually and jointly to implement a workable prevention plan, and to avoid steps that worsen the situation. More trivially, the grading of your student's essays might be your responsibility, as might making sure there is wine at tomorrow's picnic, and you might thus be required to see to it that essays are competently graded and suitable wine brought to the picnic.

Normative responsibility is distinct from two other relations called "responsibility": retrospective moral responsibility, i.e. the sort of relation an agent must stand in to decisions, actions, and outcomes in order to deserve blame or credit for them, and causal responsibility, which we have in mind when asking whether something caused something else ("is the infection responsible for these symptoms?"). ${ }^{1}$ Retrospective and causal responsibility might give rise to normative responsibilities - parents might be responsible for the wellbeing of their children because they are causally and retrospectively morally responsible for their existence. Still, normative responsibilities are themselves primarily prospective, and are often grounded in what can be done rather than in what has been done: it might be your responsibility to help the drowning child, not because you are

\footnotetext{
${ }^{1}$ It is a matter of contention whether we should acknowledge other kinds of retrospective moral responsibility, distinct from the relation that grounds blameworthiness, and if so how many. See e.g. Smith 2012.
} 
retrospectively or causally responsible for its situation, but because you are the only one who can save the child.

Normative responsibility is also distinct from two properties of agents that go by "responsibility": the property of satisfying general conditions for being held responsible - for being blamed or credited - for one's actions (capacity responsibility), and the property of having a responsible character (virtue responsibility). People also talk about "taking" responsibility, having in mind acting or committing to act as is appropriate when one is retrospectively, causally, or normatively responsible for something ("He ought to take responsibility for their failure"; "you need to take responsibility for your role in all this"; "I take responsibility for setting up a workable agreement"), and about deciding or acting responsibly, or in a responsible manner - a manner appropriate to the risks involved (manner responsibility). ${ }^{2}$

Though attributions of normative responsibilities are plentiful, such responsibilities have received surprisingly little philosophical attention compared to its normative relatives, obligations and reasons, and compared to retrospective responsibility. This chapter hopes to improve on this situation by taking on two main tasks. The first, attempted in section 1 , is to spell out the general structure of normative responsibility, in particular the relation between normative responsibilities and corresponding moral requirements and demands. We will suggest that normative responsibilities are constituted by normative requirements that the responsible agents care appropriately about how well things go in certain regards, and that moral requirements generally can be seen as straightforward upshots of requirements to care.

The second task, taken on in section 2, is to provide an overview of prominent sources of normative responsibility and its distribution among agents. Why would the children's wellbeing be the parents' responsibility? Why not the neighbor's, or the state's, or everyone's? Here we discuss a range of possible sources, including agents'

\footnotetext{
${ }^{2}$ For an influential discussion of different meanings of "responsibility", see Hart 1968: ch. 9 (cf. Vincent 2011). For manner responsibility, see e.g. Munthe 2011: ch. 5, and discussions of a "duty of care" in tort law. What concerns us here is most closely identified with what Hart calls "roleresponsibility". See also Robert E. Goodin's notion of "task responsibility" (Goodin 1995: ch. 5; Schmidtz and Goodin 1998, 150-54).
} 
abilities, costs involved in taking on the responsibility in question, retrospective responsibility for the situation, promises or contracts, and certain social relationships.

The ambition of this chapter is to contribute to the present volume on parental responsibility by providing general perspectives on normative responsibilities and their sources. To clarify the relevance of the discussion to parental responsibility, we exemplify with cases involving parents and children, but to bring out the general nature of the conclusions we want to draw, other sorts of cases are also introduced.

\section{The structure of normative responsibilities}

If one is normatively responsible for something - a child, the grading, the wine, the climate - one might be liable to be held responsible for certain states of it, such as the poor health of a child, the tardy grading, the lack of good wine, or the catastrophic climate, or for not taking reasonable measures to prevent these states. In the case of legal normative responsibilities, for example, the responsible party might be legally liable to fines, imprisonment, or other sanctions. Our focus here, however, is with moral normative responsibility. Those who fail to live up to such responsibilities are thereby liable to moral blame (cf. Miller 2001: 454).

In what follows, we will talk about what one must or must not do in order to avoid moral blame. For ease of exposition, let us say that:

MORAL REQUIREMENTS: One is "morally required to $\phi$ " insofar as failure to $\phi$ (to act, omit to act, or to be in a certain way) makes one liable to moral blame to some degree for not $\phi$-ing. ${ }^{3}$

Blame can be due for events or states of something that one is retrospectively morally responsible for, but also for actions, omissions, and certain attitudes or character traits

\footnotetext{
3 Talk of moral requirements, as defined here, is arguably closely related to and perhaps equivalent to much ordinary talk of moral obligations, of what one ought to do, and of what it would be morally wrong not to do. However, uses of "wrong", "ought", "obligatory", or "required" in moral contexts are far from univocal, and there is legitimate talk of blameless wrongdoing and blameless failures to discharge obligations, or do what one ought or is required to. Defining a notion of moral requirements in terms of liability to blame (and later analyzing responsibilities in terms of such requirement) lets us avoid these ambiguities.
} 
(being uncaring, selfish, amoral). In addition, blame can come in different degrees of seriousness, depending on how far short one falls of what is required. Correspondingly, moral requirements, as defined here, have a variety of objects, and come in various strengths.

Given MORAL REQUIREMENTS, we can now say that moral normative responsibilities are responsibilities that give rise to moral requirements. (In what follows, when we talk about "responsibilities" and "requirements", we refer to moral responsibilities and requirements unless otherwise noted.)

Agents are often subject to requirements in virtue of their responsibilities, and it might be natural to think of responsibilities as constituted by lists of requirements to do various things, perhaps in particular to ensure certain outcomes and seek information relevant to those outcomes. ${ }^{4}$ On further reflection, however, it is clear that such lists of requirements fail to capture what responsibilities are. The problem is that the requirements associated with a given responsibility seem highly context-dependent. For example, if parents are responsible for the health of a child, they are not thereby necessarily to blame for failure to prevent illness. They might not have been able to prevent the illness, ${ }^{5}$ and even if they were, there are limits to the resources they were required to spend to eliminate small risks, as well as moral constraints on the means they might have employed to help their child (such as stealing medication from another child). Similarly, although parents might typically be required to pay attention to the child's development and consider risks and options, whether failures to do so are blameworthy will depend on opportunities for taking such action (parents might be separated from children for no fault of their own), on risks involved (some children and situations might require more attention), on resources available, and again on moral constraints (for example, as children grow, parental responsibility is increasingly constrained by the children's growing autonomy). In these ways, what results parents are required to achieve or prevent, what actions they are required to perform, and what they are required to pay attention to will depend on what risks and feasible and

\footnotetext{
4 See e.g. Goodin 1995: 82; Narveson 2007: 19.

${ }^{5}$ Generally, being required to $\phi$ seems to imply being able, in some sense, to $\phi$, though the required kind of ability has been notoriously difficult to spell out.
} 
acceptable options there are. Specific requirements might also depend on the parents' degree of responsibility; one might think that one parent is more responsible for a child than the other parent, perhaps for being the one intentionally bringing about the pregnancy, or for promising to take most of the responsibility.

What might responsibilities be, then, such that they give rise to this highly contextdependent set of requirements? We propose a two-part explanation, first analyzing responsibilities as requirements to care about the object of responsibility, and then explaining how such requirements to care give rise to other requirements. We look at these parts in subsections 1.2 and 1.3, respectively. First, though, we need to say a little more about what it is to care about something, in the relevant sense.

\subsection{Caring as a disposition}

Caring about something might involve a significant emotional and motivational commitment, as is often the case with parents who care about their children. But we can also care about someone or something in a much less engaged way: perhaps we care about being prepared for a meeting, but just not very much. In general, in the sense we are after here,

CARING AS DISPOSITION: To care about $X$ is to be disposed to react and act in ways conducive to its going well with $\mathrm{X}$ in some regard: disposed to pay attention to information that might be relevant for how well it goes with $\mathrm{X}$ and to take the fact that some action would make it go better as reason for that action (i.e. to be motivated to make it go better).

So understood, caring about something is not an activity, but a disposition to engage in various mental and physical activities. Especially when $\mathrm{X}$ is a human being, such dispositions are often associated with liking $\mathrm{X}$, or being emotionally committed to the wellbeing of $\mathrm{X}$. However, caring about something, as understood here, does not necessarily imply liking it, or having positive emotional reactions to it. One might care about $\mathrm{X}$ (a child, the wine, the grading, the climate) not because one likes $\mathrm{X}$, but because one sees it as one's duty to care about $\mathrm{X}$, or stands to gain if it goes well with $\mathrm{X}$ (in the relevant regard). Likewise, the hyper-rational and unemotional Mr. Spock (of Star Trek fame) might care more strongly about a child than someone who has much stronger emotional reactions to the weal and woe of that child, in the sense that he is 
more strongly disposed to take action in her favour. (From this it should be clear that the notion of caring about at work here is wider than the notion figuring in care ethics, not being restricted to caring about people to whom one stands in particular social relations, or necessarily related to natural propensities for such interpersonal caring (see e.g. Noddings 1984). Still, we take the resulting general analysis of responsibilities and their relation to requirements to be compatible with the central tenets of care ethics and with the idea that there are requirements to care about others that can normally only be satisfied with the aid of empathy and emotional capacities.)

We will next spell out the idea that responsibilities are requirements to care. Given that caring disposes one to act and react in certain ways, this means that those who discharge their responsibilities to care will also act in certain ways. This, we will suggest, explains how responsibilities give rise to requirements to act.

\subsection{Responsibilities as requirements to care}

The first part of our explanation is that responsibilities are requirements to care: parents' responsibility for their children is a requirement that they care (in the sense outlined above) about their children. This general idea should be intuitively clear, but it is helpful to say something about the ways in which such requirements can vary, focusing in turn on each of the variables in the following formula:

RESPONSIBILITIES AS REQUIRED CARING: P's (moral normative) responsibility for an object $\mathrm{O}$ (in some regard $\mathrm{R}$ of $\mathrm{O}$, within constraints $\mathrm{C}$, to a degree $\mathrm{D}$ ) consists in the moral requirement that $\mathrm{P}$ care, within $\mathrm{C}$, with strength dependent on $\mathrm{D}$, about how well it goes with $\mathrm{O}$ with respect to $\mathrm{R}$.

Consider in turn each aspect of this general account of responsibilities:

Bearers of responsibility $(\mathrm{P})$ are paradigmatically individual moral agents, but responsibilities might also fall on groups of agents or organizations. We say more about this in section 1.4 .

Responsibilities can have a wide variety of objects $(\mathrm{O})$, such as actions ("making sure there is wine"), activities ("the production of syringes"), domains ("health care"), things ("the car"), states ("John's health"), or individuals ("your son John"). It can even stand for future states of merely possible kinds of individuals, as when one thinks that parents are responsible for the quality of life of potential offspring and that they should 
therefore choose to create one of those lives rather than another (see chapters 6 and 9 of this volume).

Depending largely the object of responsibility, the responsibility in question might relate to different ways of going well (different values of $\mathrm{R}$ ). When the object is an action, the requirement is typically to care about performing it, and performing it in ways appropriate to the context (bringing wine, good wine, at the right temperature, at the right time, in suitable containers, etc.). When the object is a domain, such as a state's health care system, such as the one described by Syurina and Feron in chapter 3 of this volume, the requirement is often to care about a variety of interacting values (accessibility of health care, equality of access, affordability, priority for the seriously ill, focus on preventive health care, etc.). In the case of most responsibilities, questions about how well it goes with the object of responsibility are multidimensional and complex. Parents will typically have to balance their caring about a child's safety from harm against their caring about her autonomy, and the responsible health care officials will have to balance the accessibility of various kinds of care and economic costs.

Constraints on the required caring are also subject to complex variation. Generally, the relevant caring is constrained by various moral concerns: it is not a sign of failure to care if parents refrain from helping their own child by stealing medication from another, for example. Forms of caring might also be restricted to wider or more narrow contexts. For example, the pediatrician's responsibility for certain children is typically understood as a requirement to care about these children's health in connection with specific doctor's appointments and follow-ups, whereas parental caring is expected to be expressed in a much wider range of contexts.

Finally, the degree (D) of the responsibility and corresponding strength of care required can vary tremendously. If someone is responsible for his child's health as well as for returning a book to the library, we think that the former responsibility carries more weight: if he has to choose between failing to protect the child's health and failing to return the book, the disposition to protect the child's health should be stronger. ${ }^{6}$

\footnotetext{
${ }^{6}$ In addition to different strengths of required care, one might want to distinguish differently strong requirements to care about something to a certain degree, perhaps with reference to the degree of blame that one would be liable to for failing to care about it to that degree.
} 
Two things are worth mentioning about the relation between RESPONSIBILITY AS REQUIRED CARE and ordinary attributions of responsibility. First, in ordinary parlance the relevant constraints and degrees of responsibility are rarely made explicit, though aspects often are, as when we say that parents are responsible for the child's safety or behaviour, or that paediatricians are responsible for the health of children in their care. Second, what we ordinarily think of as "responsibilities" are relatively significant requirements to care. ${ }^{7}$

\subsection{Responsibilities and requirements to act}

To understand how responsibilities give rise to requirements of various kinds, we need not only an account of responsibilities in terms of requirements to care, but also an account of the relation between requirements to care and other requirements, in particular requirements to act. Here we propose that in contexts where the required caring about something would ensure (in a normal fashion) that one acts in certain ways - that one feeds a child, or that one does not give it alcoholic beverages - this gives rise to requirements to act in these ways.

Our account builds on four ideas. The first is that under the right circumstances, that we care about something ensures that we perform certain actions, come to know certain things, develop certain capacities, have certain emotional reactions, and care about certain other things. This is no accident, of course, given that caring about something is a disposition to notice and act on information in ways conducive to the object of care. For example, the normal way in which caring ensures that an action is performed is by (a) ensuring recognition of reasons suggesting that the action would be conducive to the object of care in the relevant way, where (b) this recognition in turn ensures the action in question. Under the right circumstances, parents' caring about a child ensures that they recognize when it needs nourishing, health care, or emotional support, and that they take action to satisfy these needs. In the same way, caring about something can ensure that we learn facts relevant to the object of care, by ensuring that

\footnotetext{
7 Hart (1968: 213) tentatively suggests that some duties are "singled out as responsibilities" because they "require care and attention over a protracted period of time". However, it is natural to talk about responsibilities even in the case of very simple but highly significant actions.
} 
we recognize or actively seek out the relevant information. Caring about something might also ensure that we have certain emotional reactions and enter into moods of the sort preparing us for the relevant sorts of action, such as fear, anger, determination, curiosity, or compassion. In the case of long-term responsibilities, caring might also ensure that we develop certain capacities that might make caring more efficient, through a general concern for how our behaviour affects the object of care. Finally, caring about something can non-accidentally ensure that we care about any number of other things because we see these as positively affecting the object of care: a parent might care about the temperature in the room or the quality of the food because he cares about his children's health, for example.

Second, in contexts where appropriate caring would have ensured an action or some capacity or emotional or cognitive state in these ways, the lack of such action, knowledge, or capacity is straightforwardly explained by lack of appropriate care. If caring as required would ensure feeding one's child, failure to feed the child must be due to failure to care as required. Conversely, if caring as required would not ensure feeding one's child - perhaps it doesn't need feeding at the moment, or there are more important things to attend to - failure to feed one's child might not be explained by failure to care.

Third, it is exactly when one's failure to $\phi$ (to act, know, feel, or be capable of something) is the normal, straightforward upshot of lack of appropriate caring that one is liable to moral blame for failing to $\phi .{ }^{8}$ If one failed to $\phi$ for some other reason, this cannot be ground for moral blame.

Fourth, because one is morally required to $\phi$ just in case one would be to blame for not $\phi$-ing - this is how we defined moral requirements - there is a requirement that one act in ways that are ensured in a normal fashion by the required caring.

The upshot of these four ideas is:

\footnotetext{
8 For the connection between blame and quality of will, see e.g. Strawson 1982[1962]: Arpaly 2006; McKenna 2012. For the connection between blame and normal explanations of objects of blame in terms of agents' quality of will, see Björnsson 2011; Björnsson and Persson 2012; 2013. For some relations between individual and group responsibilities or requirements, see Björnsson (forthcoming).
} 
REQUIRED $\Phi$-ING AS ENSURED BY REQUIRED CARING: P is morally required to $\phi$ if, and only if, were $\mathrm{P}$ to care about things in ways that are morally required of $\mathrm{P}$, this would ensure, in normal fashion, that $\mathrm{P} \phi{ }^{9}$

REQUIRED $\Phi$-ING AS ENSURED BY REQUIRED CARING captures the close connections between requirements to act, quality of will (whether one cares as required), and blame. The proposal also accommodates the idea that agents are required to $\phi$ only insofar as they can $\phi$, in a sense that implies strong capacity to $\phi$ : proper caring must ensure the fulfilment (in a normal way). If morally required caring would only ensure that $\mathrm{P}$ tried to $\phi, \mathrm{P}$ would only be required to try. At the same time it allows that one can act as morally required - feed a child, say — without caring as required, or without thinking that the act is required (cf. Ross 1930: 5-6, 42-46).

Given RESPONSIBILITY AS REQUIRED GARING and REQUIRED $\Phi$-ING AS ENSURED BY REQUIRED CARING, it is easy to see how responsibilities can give rise to a variety of requirements to act, depending on the exact nature of the responsibility and the context. But it might also be that very few specific actions are ensured by required caring, generating few requirements to act and leaving great room for the discretion of the responsible party. This will depend on the situation and the nature of the required caring.

\subsection{Subjects of responsibility: individuals, organizations, groups}

Normative responsibilities are not only attributed to human agents, but also to so-called corporate agents, such as corporations, nations, Non-Governmental Organisations (NGOs), and departments of larger organizations, as well as to groups of people, such as the parents of a child, the affluent countries of the world, or the bystanders jointly capable of preventing a crime. Such attributions make sense given the nature of normative responsibility and the nature of normative requirements as outlined in section 1. Individual agents, organizations and groups are commonly understood as liable to blame for failing to take relevant considerations into account. Corporations are frequently blamed for not taking into account environmental effects of their actions,

\footnotetext{
${ }_{9}$ As noted above (n. 3), moral requirements are arguably closely related to moral obligations. For motivation of the corresponding account of moral obligations, see Björnsson 2014: 114-116.
} 
affluent countries blamed for not doing enough to prevent catastrophic climate change, and pairs of parents collectively blamed for not taking proper care of their children. ${ }^{10}$ If it makes sense to direct blame at corporate agents and groups in these ways, it also makes sense to attribute responsibilities to them.

That an organization or group is responsible for something does not mean that each of its members is responsible for the same thing with respect to the same aspect and within the same constraints. Consider a couple, Alex and Billy, who adopts a child. Before adopting, it was clear to both that Alex's ongoing projects would be hard to combine with being fully engaged in raising the child. It was also clear that Billy wanted a child more and was prepared to take on most of the responsibility for the child, but that Alex would be ready to step in if necessary. Under these circumstances, one might think that Alex and Billy are jointly responsible for the child's welfare, but that the care required from Alex is more circumscribed and conditional than that required by Billy.

The example also illustrates a distinction between primary and secondary responsibilities, the latter being responsibilities that are conditional on the failure of others to live up to their responsibilities. If Billy's capacity to take care of the child would diminish, or if Billy abandons the child, Alex might now have full responsibility for the child. Similarly, if both Alex and Billy would fail, for lack of capacity or lack of caring, responsibility for the child might fall on some government agency or extended family, who have conditional or circumscribed reasons to care. ${ }^{11}$

\footnotetext{
10 The appropriateness of blame directed at corporations or loosely structured groups of people is a controversial matter. For some defenders, see e.g. Held 1970, French 1984, Rovane 1998, Kutz 2000, List and Pettit 2011. For criticism, see e.g. Corlett 2001, Haji 2006, McKenna 2006, Miller 2007. For our defense, see Björnsson 2011; Björnsson 2014; Björnsson and Hess 2016.

11 Related phenomena are those of delegated and transferred responsibility, as when parents leave their child in the care of a babysitter for a few hours, delegating some of their responsibilities, or when they place a child for adoption, transferring responsibilities to the new parents. For discussion of ethical issues with abandoning a child, as compared to putting it up for adoption, see Giordano 2007.
} 


\section{Sources of special normative responsibilities}

The main purpose of this section is to give an overview of the most common sources of special responsibilities, i.e. the sources that differentiate responsibilities between different agents. ${ }^{12}$ To identify the sources of responsibility falls short of exhaustively stating the conditions under which someone is normatively responsible, or of providing a full-fledged theory of responsibility. Instead, the question about sources concerns what factors give rise to responsibilities if they are not undermined by other factors. To identify sources of responsibility is thus to identify prima facie principles of responsibility.

We will suggest that there might be at least six distinct sources of normative responsibility, namely (1) capacity, (2) retrospective or causal responsibility, (3) benefits, (4) agreements, (5) just laws and social norms, and (6) social ties. In distinguishing these sources, we are not implying that there cannot be others. Nor are we assuming that the listed sources will be rock bottom in a final theory of responsibility. Perhaps they are best seen as grounded in more fundamental normative considerations: consequentialist, rule-consequentialist, or contractualist (see e.g. Goodin 1988; Hooker 2000). For example, one might think special responsibilities might be grounded in general impartial responsibilities, motivated by the need for a moral division of labour, as proposed by Goodin (1988) in the case of responsibilities towards compatriots. The idea is that we all have general moral responsibilities to all persons, e.g. to help children in need. But for these responsibilities to be best fulfilled, they need to be distributed so that it is clear who should do what for whom. Applied to the case of parental responsibilities, the idea could be to assign primary responsibility for children to parents, while others have mere secondary or other residual responsibilities, because this division of responsibilities would have best consequences overall. In this section, however, our purpose is to canvas

\footnotetext{
12 In focusing on special responsibilities, we ignore the question of whether there are universal responsibilities, e.g. a consequentialist responsibility to make the world a better place or deontological responsibilities to, respectively, help and not harm, and how those would be grounded. (So-called "imperfect duties" in deontological theory roughly correspond to what we call "responsibilities". Such duties are not requirements to perform specific actions on every occasion of a certain sort, but can naturally be thought of as requirements to care.)
} 
the variety of intuitively plausible sources of responsibilities, without attempting to provide a unified justification.

\subsection{Capacity and cost}

In some cases, we are responsible for bringing about a morally important outcome because we are particularly well placed to do so. For example, if a child is drowning and you are the only person around who can prevent this, it seems that it is your responsibility to save the child, at least absent extremely strong reasons not to. Often, more than one agent or group is capable of achieving the relevant end. In such cases, their relative capacity might determine the extent to which they are responsible for the outcome. ("With greater power comes greater responsibility".) In general terms, something like the following principle seems plausible (leaving open exactly what counts as a morally important outcome):

CAPACITY: The party (individual or group) that has most capacity to produce a morally important outcome is, ceteris paribus, responsible for doing so. (Cf. Miller 2001: 460.)

As Miller (2001) points out, capacity to produce an outcome can be regarded as a function of effectiveness (what the agent can do, or how likely she is to succeed) and cost (how costly it is for her to exercise her abilities). This suggests that CAPACITY might be divided as follows:

LEAST COST: The party for which it is least costly to produce a morally important outcome is, ceteris paribus, responsible for doing so.

EFFECTIVENESS: The party for which success is most likely is, ceteris paribus, responsible for producing a morally important outcome.

LEAST COST might imply that new technologies (like cell phones) increase responsibility for helping by lowering costs (cf. Wenar 2007). EFFECTIVENESS can explain why being the only one (or one of a few) who can satisfy someone's needs might give rise to special responsibilities, e.g. to one's children.

As formulated, these principles are obviously rough first drafts: The existence of the responsibility as well as its weight will presumably depend on how important the outcome is, and how capable the agent is of achieving it. Moreover, much could be said 
about the ceteris paribus clause. Depending on what other sources of responsibility are at play, CAPACITY might not apply, and high enough costs might void responsibility altogether. If you can only save the drowning child by risking your own life, you might not be responsible for saving the child, even if you are the person who would be most likely to succeed (Wenar 2007, 260). ${ }^{13}$ Finally, the principles, as stated here, are most plausibly concerned with primary responsibilities. Corresponding principles could be formulated for secondary responsibilities.

\subsection{Retrospective and causal responsibility}

Our past actions might also be a source of normative responsibility. For example, retrospective moral responsibility for harmful outcomes can give rise to a normative responsibility to clean up some mess, deal with the harm, or compensate victims. But other kinds of retrospective responsibility might likewise give rise to normative responsibilities. If one is retrospectively responsible for a situation that risks leading to harm, one might be normatively responsible for preventing that harm. Similarly, if one is retrospectively responsible for a situation in which something needs to be done to prevent harm, one might be normatively responsible for preventing it even when others would definitely prevent the harm and there thus is no real risk. For example, having knowingly conceived a child, parents might be retrospectively responsible for the existence of a vulnerable being who will be harmed unless it gets copious amounts of help. Even though no harm has been done and no risk created because others will provide help if the parents do not, it might seem that the parents are normatively responsible for helping the child because they brought it into existence. Summing all this up in general terms, it seems that:

RETROSPECTIVE RESPONSIBILITY: The degree to which $\mathrm{P}$ is normatively responsible for setting things right or preventing harm is, ceteris paribus,

\footnotetext{
${ }^{13}$ One might think that responsibilities based on capacity and costs follow straightforwardly from universal responsibilities to produce morally important outcomes (cf. note 12 above): if one cares about this, one will care particularly about contributing in cases where one can easily and effectively do so.
} 
positively correlated with the degree to which $\mathrm{P}$ is retrospectively responsible for the situation calling for these actions.

The most discussed special case is one where $\mathrm{P}$ is normatively responsible for compensating some identifiable person or persons for harm for which $\mathrm{P}$ is retrospectively responsible (cf. Miller 2001, p 458). However, we might also have normative responsibilities in virtue of being retrospectively responsible for harming or endangering some valuable material thing, sacred order, or abstractly identified group (e.g. future generations).

$\mathrm{P}$ here can be an individual agent, but also a group jointly retrospectively responsible for the situation. The parents might be jointly normatively responsible for their child in virtue of having jointly knowingly and willingly brought it into existence, and the major industrial countries might be jointly normatively responsible for preventing catastrophic climate change in virtue of having knowingly created or exacerbated the threat. ${ }^{14}$

Something like RETROSPECTIVE RESPONSIBILITY is fairly uncontroversial. But it might also be thought that mere causal responsibility ("contribution" or "participation") can be a source of normative responsibility, even in the absence of moral retrospective responsibility. For example, if you have (blamelessly) harmed someone or someone's property or put someone in danger, you might thereby be normatively responsible, to some degree or other, for setting things right or preventing harm:

CAUSAL RESPONSIBILITY: The degree to which $\mathrm{P}$ is normatively responsible for setting things right or preventing harm is, ceteris paribus, positively correlated

\footnotetext{
${ }^{14}$ Regarding collective cases, see Ashford 2007; Pogge 2007; cf. also the "polluter pays principle" in the context of environmental impacts. For discussion of joint retrospective responsibility, with a note on how it depends on normative requirements, see Björnsson 2011. Interestingly, it has been suggested that causal responsibility might be unnecessary for retrospective responsibility in collective contexts: the latter might only require that one has participated (non-causally) in a harmful collective action (Kutz 2000).
} 
with the degree to which $\mathrm{P}$ is causally responsible for the situation calling for these actions. ${ }^{15}$

The most familiar case, again, would be one where $\mathrm{P}$ is responsible for compensating some identifiable person or persons that $\mathrm{P}$ has harmed. But if one accepts a principle like this, it might have wider consequences. For example, even a man and a woman who conceive a child in spite of taking all reasonable contraceptive measures (i.e. unknowingly and unwillingly) could have special responsibilities for the child merely because their having sex was crucial for bringing the child into existence. ${ }^{16}$

As in the case of the capacity principles above, these two responsibility principles are best seen as rough drafts. Both are mere ceteris paribus principles, and the degree to which normative responsibility results is presumably dependent on the degree of causal or retrospective responsibility, which in turn depends on "the way and extent to which the agent is related to the production of that situation" (Haydar 2005, 311).

\subsection{Benefiting}

If you have benefited from someone's help, you might be responsible for reciprocating. For example, you might have a filial responsibility to take care of your aging parents because of what they have done for you over the years. Similarly, according to the socalled Hart-Rawls principle of fairness, if one has benefitted from the cooperative scheme of some group, one has an obligation to reciprocate. ${ }^{17}$ Benefiting from the actions of one or more others might thus be a source of responsibility:

BENEFITING FROM HELP: If P has benefited from Q's actions (where Q can be an individual agent, a group, or perhaps a society as a whole), $\mathrm{P}$ is, ceteris paribus, responsible for reciprocating, i.e. for helping or supporting $Q$.

15 Cf. Barry's (2005, 280) contribution principle, which holds "that agents are responsible for addressing acute deprivations when they have contributed, or are contributing, to bringing them about".

16 Cf. Archard's $(2010,127)$ suggestion that "those who cause children to exist thereby incur an obligation that they are adequately cared for".

17 See Arneson 2013 for discussion and amendments or clarifications of the principle in response to criticism. 
More controversially, one might think that those who benefit from some harm or injustice (e.g. from an unjust system) might have a normative responsibility to help setting things right. For example, the Beneficiary Pays Principle is invoked in the context of climate justice, where it is sometimes argued that "the beneficiaries of activities that cause climate change should shoulder the [relevant] costs" (Page 2012: 304). The costs here might be costs involved in compensating for harm or restoration for injustice, but also costs for preventing harm that would result from the activities in question:

BENEFITING FROM HARM, INJUSTICE OR DANGER: If $\mathrm{P}$ has benefited from something that has brought morally important downsides (injustice, harm, danger) that calls for restoration, compensation or prevention, then $\mathrm{P}$ is, ceteris paribus, responsible for contributing to such restoration, compensation or prevention, to a degree dependent on the benefits derived.

In the most typical case, $\mathrm{P}$ has benefited from some injustice or harm that some other agent has perpetrated against an identifiable person (or persons) $Q$ and has a resulting responsibility for compensating $\mathrm{Q}$.

Again, the responsibility arising from benefits will depend on a variety of further considerations. Some people defend a restricted version of BENEFITING FROM HARM, INJUSTICE OR DANGER. For example, Caney (2010) suggests that benefiting and causal responsibility only give rise to normative responsibility in conjunction with each other (p. 210; cf. Miller 2001).

\subsection{Promises, contracts, and agreements}

Promises, agreements and contracts can also be sources of responsibility. For example, we might be responsible for making sure there is enough wine at a dinner party because we have voluntarily agreed to bring the wine. The same thing holds when the promise or agreement takes the form of a legally binding contract, e.g. in business contexts. If you have signed a contract which says that you will deliver a certain service at a certain time, you are not just legally responsible for doing so, but also, in most cases, morally normatively responsible. What these phenomena have in common seems to be that they involve the voluntary agreement or commitment to do something. This suggest that: 
AGREEMENT: If $\mathrm{P}$ has voluntarily agreed to $\phi$, then $\mathrm{P}$ is, ceteris paribus, responsible for $\phi$-ing. ${ }^{18}$

If one accepts this proposal and takes promises and contracts to be sources of responsibility because they are voluntary agreements, one might also further recognize implicit promises, contracts or agreements as sources of responsibility. Whether one should understand "voluntarily agreed" in the context of this principle as including implicit agreements will presumably depend on how one understands explicit agreements and their relation to responsibilities. Perhaps explicit agreements bind by giving rise to justifiable expectations grounded in mutual benefit; perhaps benefiting from some social order (laws, customs) thus constitutes relevant tacit consent and grounds responsibilities, as benefiting without consent would be unfair. The point here, however, is merely to note implicit agreements as a possible source of responsibility. ${ }^{19}$

\subsection{Laws and norms}

It is easy to imagine different ways of assigning parental responsibilities, and perhaps different ways that could be justly enforced (by law, or by milder forms of social pressure) in a society. Suppose that in one society, there is a norm, justly socially enforced, that genetic parents materially support their offspring (unless incapable, and unless the job has been justly transferred to some other party). Then it might seem that genetic parents in that society would (normally) be responsible for supporting their offspring, in virtue of the existence of that norm. Generalizing, one might think that:

JUST SOCIAL NORMS: If $\mathrm{P}$ is required by just social norms to $\phi$, then $\mathrm{P}$ is, ceteris paribus, responsible for $\phi$-ing.

\footnotetext{
${ }^{18}$ For a helpful introductory discussion, see Jeske 2014.

19 The problem of tacit consent has received much attention in political philosophy from Hobbes, Locke, and onwards, in connection with the problem of political obligation, i.e. of when a person has a moral duty to obey the laws of her country or state. For an introductory overview of this problem, see Wolff 2006.
} 
As in the case of other sources of responsibility, the weight of the responsibility might vary (depending on how just the norm is) and this particular consideration might be undercut or outweighed by a variety of others.

While it seems clear that we typically have responsibilities to conform to justly enforced social norms, it is not entirely clear that such norms provide a further source of responsibility, independent of the sources discussed in the previous sections. For example, when socially enforced norms of both formal and informal kinds are voluntarily consented to, explicitly or implicitly, AGREEMENT implies that it is the responsibility of the consenting parties to conform to such norms. By BENEFITING FROM HELP, it is the responsibility of those who have benefited from a cooperative scheme guided by the norms to reciprocate by conforming. And by CAPACITY, it is the responsibility of those who can conform to just norms to do so, insofar as conformity to justly enforced norms contributes to morally important outcomes. Given how difficult it is to find applications of JUST SOCIAL NORMS where neither of these other considerations is at work, it is difficult to find direct intuitive support for thinking that just social norms provide a further independent source of responsibilities. For this reason, we refrain here from taking a stand on whether it does.

\subsection{Roles and special relationships}

Responsibilities are often associated with roles. In fact, the association is so strong that what we call normative responsibility is sometimes referred to as "role-responsibility". Hart (1968) introduced this notion by pointing out that

whenever a person occupies a distinctive place or office in a social organization, to which specific duties are attached to provide for the welfare of others or to advance in some specific way the aims or purposes of the organization, he is properly said to be responsible for the performance of these duties, or for doing what is necessary to fulfil them. Such duties are a person's [role] responsibilities. (p. 212)20

\footnotetext{
${ }^{20}$ Here, Hart extends the sociological notion of a role "to include a task assigned to any person by agreement or otherwise" (p. 213). However, Hart takes only a subset of the duties connected to roles to constitute responsibilities (cf. n. 9).
} 
This makes it natural to think of roles as independent sources of normative responsibility, i.e. to assume that we have a number of special responsibilities in virtue of our social or professional roles.

Whether this is plausible depends on how roles are understood. Suppose that we understand roles as themselves constituted by moral requirements and responsibilities. Then the role would not be so much the source of these requirements as their upshot. But suppose, instead, that roles are constituted by laws or other social norms tied to positions in a social system. Then roles could indeed be sources of requirements, either because the norms in questions were just (by JUST SOCIAL NORMS), or because people agree with the norms constituting the roles when they occupy these roles (by AGREEMENT). ${ }^{21}$ This seems particularly clear in the case of professional roles that are largely defined by contracts and laws, and perhaps many other roles, including those of a friend, partner, or parent, can at least partly be similarly defined by social norms. Moreover, norms associated with particular roles might give those occupying the roles certain social capacities, capacities that are in turn sources of responsibility (by CAPACITY). Relatedly, roles might typically be associated with and perhaps even defined by various non-normative capacities to care. Parents will typically be particularly strongly disposed to care about their children, and friends to care about their friends, and weaker social relations can give rise to relations of solidarity among members of social groups, making it easier for them to help. ${ }^{22}$ Correspondingly, children have emotional needs in relation to their regular caretakers that might not be easily satisfied by others. The point here is not the trivial one that people in close relationships do in fact care about each other. Rather, the idea is that such relationships might give rise to normative responsibilities, e.g. through CAPACITY. In giving rise to responsibilities for these sorts of reasons, however, roles are clearly parasitic on the other sources already mentioned. It is questionable whether they provide a further, independent sources of responsibilities.

Similar things can be said about the suggestion that community membership or special social relations of various kinds are sources of responsibilities. For example,

\footnotetext{
21 See e.g. Hardimon 1994.

${ }^{22}$ Cf. Feinberg (1968), who takes relations of solidarity to ground collective responsibility.
} 
David Miller (2001, 462) suggests that remedial responsibilities - responsibilities to put bad situations right - are in part distributed based on "special ties of various kinds such as those that exist within families, collegial groups of various kinds, nations, and so forth". These ties, he thinks, can arise from "shared activities and commitments, common identities, common histories, or other such sources". Depending on how they are understood, these characterizations raise the same question as appeals to roles. If the ties are understood in normative terms, as requirements, the question is from where they arise. But it is also easy to see how social relations can give rise to requirements, given the sources we have already covered. Many social or intimate relationships are subject to just social norms, or expectations involving voluntary agreement, or relations involving caring and corresponding emotional needs yielding special capacity to help, or relations of benefit. If these are the grounds of responsibilities, however, social ties do not provide sources beyond what has already been covered. ${ }^{23}$

Still, we want to suggest that some social ties are further sources of responsibilities. Consider a case involving a minimal history of cooperation:

No complete Stranger: Two people, $\mathrm{Q}$ and $\mathrm{R}$, have fallen into a river, and you can reach out and help one onto dry ground. Both are at equal distance and would be equally easy to help, but whereas $Q$ is a complete stranger, you recognize R from yesterday. Someone had asked how to get to City Hall, and you and $\mathrm{R}$ had both provided partial answers in a brief but cooperative effort.

In this situation, it seems to us that your responsibility to help $\mathrm{R}$ is stronger than your responsibility to help Q: the mere fact that you share a brief cooperative history makes a difference. Still, it is not clear that any of the other sources mentioned here can explain this. Moreover, the extent of the cooperative history seems to matter: if you have had some cooperative interaction with $\mathrm{Q}$ but a much more extensive interaction with $\mathrm{R}$, this too would make a difference, and one that could trump other sources of responsibilities. Perhaps, then, at least some kinds of social ties constitute further sources of at least remedial responsibilities:

23 Similar things can be said about relations figuring in Iris Marion Young's (2013) "connection model" of forward-looking responsibility for injustice. 
SOCIAL TIES: If $\mathrm{Q}$ and $\mathrm{R}$ need help and $\mathrm{P}$ is more strongly linked to $\mathrm{Q}$ than to $\mathrm{R}$ by relevant social ties (such as histories of cooperative interaction), then $\mathrm{P}$ has greater (remedial) responsibilities towards $\mathrm{Q}$ than towards $\mathrm{R}$, ceteris paribus.

For reasons of space, we refrain here from trying to determine exactly how to understand the relevant social ties, or whether they extend beyond cooperative histories to other social or communal relations of the sort mentioned by Miller. ${ }^{24}$ The formulation of SOCIAL TIES, perhaps even more than those of the other principles discussed in this section, is best understood as a first draft. Much more can be said about the nature of the relevant social ties and their relation to roles, community membership and intimate relations, about the weight and contents of the resulting responsibilities, and about further extensions or qualifications of the principle. ${ }^{25}$ Still, even restricted to this one kind of social tie, the principle might have important consequences for responsibilities towards friends, lovers, spouses, and coworkers, as well as towards one's parents or children: all these relations typically involve rich histories of cooperative interaction.

\section{Conclusion}

In section 1, we proposed that moral normative responsibilities should be understood as moral requirements to care about the object of responsibility. It is such requirements, we suggested, that give rise to the variety of other requirements that seem to follow from our responsibilities, including requirements to act, and requirements to care about acting in certain ways. In section 2 , we have briefly discussed what we take to be the more obvious kinds of sources of special responsibilities.

As we have indicated, most of these kinds of sources seem relevant for various forms of parental responsibility, and for the theme of this volume. ${ }^{26}$ But the sources also

\footnotetext{
24 Cf. Bell (2012), section 3, for a useful distinction between three types of communities, namely communities of place, communities of memory, and "psychological communities", or "communities of face-to-face personal interaction governed by sentiments of trust, co-operation, and altruism".

25 Cf. Scheffler (1997), who suggests that special relationships only give rise to responsibilities when people have reason to value these relationships.

${ }^{26}$ For an earlier discussion of some of these issues, see Brennan \& Noggle (2007).
} 
interact with each other and raise numerous complications, many of which are discussed in detail in other chapters. How much weight does one type of responsibility have compared to other responsibilities? What exactly are parents responsible for, and what are the constraints (see chapters 2, 4, 5, 6, 8, 11, in this volume)? How much information can, or need they seek; how much can or should they control (see chapters $3,8,11$, in this volume)? What responsibilities do parents have towards a fetus, or to children at various stages of development (see chapters 8, 9, 10, 12, 13)? When parents can control which child comes into existence, are they responsible for choosing children that can have a higher quality of life, or are they merely responsible for the quality of life the child they actually bring into existence (see chapters 9, 10)? What are the rights and responsibilities of others when parents fail to discharge their own responsibilities (see chapters 3,7$)$ ? Though we have done nothing in this chapter to answer these questions specifically, what we have provided are some general perspectives that can hopefully guide the reader in thinking further about these issues.

\section{Acknowledgements}

The chapter has benefitted from a wide range of useful comments from participants at seminars at Umeå University and University of Gothenburg, as well as from written comments by Kalle Grill, Jonas Nilsson, the editors of this volume, and an anonymous referee.

\section{References}

Archard, D. (2010). The Obligations and Responsibilities of Parenthood. In D. Archard and D. Benatar (eds.), Procreation and Parenthood: The Ethics of Bearing and Rearing Children (pp. 103-127). Oxford: Oxford University Press.

Arneson, R. (2013). Paternalism and the Principle of Fairness. In C. Coons and M. Weber (eds.), Paternalism (pp. 134-56). Cambridge: Cambridge University Press.

Arpaly, N. (2006). Merit, Meaning, and Human Bondage: An Essay on Free Will. Princeton, NJ: Princeton University Press.

Ashford, E. (2007). The duties imposed by the human right to basic necessities. In T. Pogge (ed.), Freedom from poverty as a human right: Who owes what to the very poor? (pp. 183-218). Oxford: Oxford UP. 
Barry, C. (2005). Applying the contribution principle. In C. Barry and T. Pogge (eds.), Global Institutions and Responsibilities: Achieving Global fustice (pp. 280-297). Oxford: Blackwell.

Bell, D. (2013). "Communitarianism", The Stanford Encyclopedia of Philosophy (Fall 2013 Edition), Edward N. Zalta (ed.), URL = <http://plato.stanford.edu/archives/fall2013/entries/communitarianism/>.

Björnsson, G. (Forthcoming). Individual and shared obligations. In Philosophy and climate change, eds. M. Budolfson, T. McPherson and D. Plunkett. Oxford: Oxford University Press.

Björnsson, G. (2014). Essentially Shared Obligations. Midwest Studies in Philosophy, 38(1), 103-20.

Björnsson, G. (2011). Joint Responsibility without Individual Control: Applying the Explanation Hypothesis. In J. van den Hoven, Jeroen, I. van de Poel, \& N. Vincent (eds.), Compatibilist Responsibility: Beyond Free Will and Determinism (pp. 181-99). Dordrecht: Springer.

Björnsson, G. \& Hess, K. M. (2016). Corporate Crocodile Tears? On the Reactive Attitudes of Corporations. Philosophy and Phenomenological Research, Early View, doi: $10.1111 /$ phpr. 12260

Björnsson, G. \& Persson, K. (2013). A Unified Empirical Account of Responsibility Judgments. Philosophy and Phenomenological Research, 87(3), 611-39.

Björnsson, G. \& Persson, K. (2012). The Explanatory Component of Moral Responsibility. Noûs, 46(2), 326-54.

Brennan, S \& Noggle, R. (eds.) (2007). Taking Responsibility for Children. Waterloo: Wilfrid Laurier University Press.

Caney, S. (2010). Climate change and the duties of the advantaged. Critical Review of International Social and Political Philosophy, 13(1), 203-228.

Corlett, J. A. (2001). Collective Moral Responsibility. Fournal of Social Philosophy, 32(4), 57384.

Feinberg, J. 1968. Collective responsibility. The Journal of Philosophy 65(21): 674-688.

French, P. A. (1984). Collective and Corporate Responsibility. New York: Columbia University Press.

Giordano, S. (2007). Crimes and Misdemeanours: The Case of Child Abandonment. Fournal of Medical Ethics, 33(1), 28-34. 
Goodin, R. E. 1995. Utilitarianism as a Public Philosophy. Cambridge: Cambridge University Press.

Goodin, R. E. (1988). What is so special about our fellow countrymen? Ethics, 98(4), 663686.

Haji, I. (2006). On the Ultimate Responsibility of Collectives. Midwest Studies in Philosophy, 30(1), 292-308.

Hardimon, M. (1994). Role Obligations. The Joumal of Philosophy, 91(7), 333-363.

Hart, H. L. A. (1968). Punishment and Responsibility. Oxford: Oxford University Press.

Haydar, B. (2005). Extreme poverty and global responsibility. In C. Barry and T. Pogge (eds.), Global Institutions and Responsibilities: Achieving Global Fustice (pp. 310-322). Oxford: Blackwell.

Held, V. (1970). Can a Random Collection of Individuals Be Morally Responsible? The Journal of Philosophy, 67(14), 471-481.

Hooker, B. (2000). Ideal Code, Real World: A Rule-Consequentialist Theory of Morality. Oxford: Clarendon Press.

Jeske, D. (2014). Special obligations, The Stanford Encyclopedia of Philosophy (Spring 2014 Edition), Edward N. Zalta (ed.), URL = <http://plato.stanford.edu/archives/spr2014/entries/special-obligations/>.

Kutz, C. (2000). Complicity: Ethics and Law for a Collective Age. Cambridge: Cambridge University Press.

List, C. \& Pettit, P. (2011). Group Agency: The Possibility, Design, and Status of Corporate Agents. Oxford: Oxford University Press.

McKenna, M. (2006). Collective Responsibility and an Agent Meaning Theory. Midwest Studies in Philosophy, 30(1), 16-34.

McKenna, M. (2012). Conversation and Responsibility. New York: Oxford University Press.

Miller, D. (2001). Distributing responsibilities. Fournal of Political Philosophy, 9(4), 453-471.

Miller, S. (2006). Collective Moral Responsibility: An Individualist Account. Midwest Studies in Philosophy, 30(1), 176-93.

Munthe, C. (2011). The Price of Precaution and the Ethics of Risk. Dordrecht: Springer.

Narveson, J. (2007). Parental Responsibility. In S. Brennan \& R. Noggle (eds.), Taking Responsibility for Children (pp. 19-45). Waterloo: Wilfrid Laurier University Press.

Noddings, Nel 1984: Caring: A Feminine Approach to Ethics and Moral Education. University of California Press. 
Page, E. A. (2012). Give it up for climate change: A defence of the beneficiary pays principle. International Theory, 4(2), 300-330.

Pogge, T. (2007). Severe poverty as a human rights violation. In T. Pogge (ed.), Freedom from poverty as a human right: Who owes what to the very poor? (pp. 11-53). Oxford: Oxford University Press.

Ross, W. D. (1930/2002). The Right and the Good. Oxford: Clarendon Press.

Rovane, C. A. (1998). The Bounds of Agency: An Essay in Revisionary Metaphysics. Princeton, NJ: Princeton University Press.

Schmidtz, David \& Goodin, Robert E. (1998). Social Welfare and Individual Responsibility. Cambridge: Cambridge University Press.

Smith, A. M. (2012). Attributability, Answerability, and Accountability: In Defense of a Unified Account. Ethics, 122(3), 575-89.

Scheffler, S. (1997). Relationships and Responsibilities. Philosophy and Public Affairs, 26(3), 189-209.

Strawson, P. F. (1982[1962]). Freedom and Resentment. In G. Watson (ed.), Free Will (pp. 59-80). Oxford: Oxford University Press.

Vincent, Nicole A. (2011). A Structured Taxonomy of Responsibility Concepts. In N.A. Vincent., I. van de Poel \& J. van den Hoven (eds.), Moral Responsibility (15-35). Dordrecht: Springer Netherlands.

Wenar, L. (2007). Responsibility and severe poverty. In T. Pogge (ed.), Freedom from poverty as a human right: Who owes what to the very poor? (pp. 255-274) Oxford: Oxford University Press.

Wolff, J. (2006). An Introduction to Political Philosophy, revised edition. Oxford: Oxford University Press

Young, I. M. (2013). Responsibility for Fustice. Oxford: Oxford University Press. 